\title{
Autonomous ships for container shipping in the Arctic routes
}

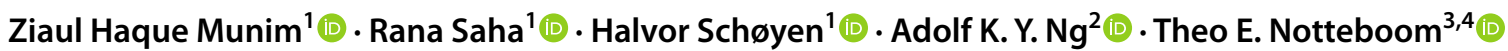

Received: 9 September 2020 / Accepted: 29 June 2021 / Published online: 15 July 2021

(c) The Author(s) 2021

\begin{abstract}
This study investigates the competitiveness of various autonomous ship categories for container shipping in the Arctic route. We propose a multi-criteria decision-making (MCDM) framework using four ship categories as alternatives and eight criteria for competitiveness evaluation. We analyse collected data using the Best-Worst Method (BWM), one of the recently developed MCDM methods. The findings reveal that operating expenses, navigation aspects, and environmental protection are the three most important criteria for deploying autonomous ships in the Arctic route. Among the three investigated autonomous ships alternatives, the semi-autonomous ship operated from a shore control centre (SCC) is prioritized for Arctic shipping in the foreseeable future, when benchmarked against the conventional ship. The SCC-controlled semi-autonomous ship alternative is competitive in the majority of the considered criteria including operating expenses, capital expenses, navigation, ship-shore and ship-ship communication, search and rescue, and environmental protection.
\end{abstract}

Keywords Autonomous ship $\cdot$ Arctic shipping $\cdot$ Multi-criteria decision-making $\cdot$ Northern sea route $\cdot$ Best-worst method

\section{Introduction}

Sea ice has been declining continuously with a reduction of about $40 \%$ in the past 40 years [1]. This decline leads to increased interest and efforts to establish new sea trade routes via the Arctic [2]. The Arctic offers three shipping routes-the Northern Sea Route (NSR), the Northwest

Ziaul Haque Munim

ziaul.h.munim@usn.no

Rana Saha

saha.usn@gmail.com

Halvor Schøyen

halvor.schoyen@usn.no

Adolf K. Y. Ng

adolfng@uic.edu.cn

Theo E. Notteboom

theo.notteboom@ugent.be

1 Faculty of Technology, Natural and Maritime Sciences, University of South-Eastern Norway, Horten, Norway

2 Division of Business and Management, Beijing Normal University-Hong Kong Baptist University United International College, Zhuhai, China

3 Maritime Institute, Faculty of Law and Criminology, Ghent University, Ghent, Belgium

4 Antwerp Maritime Academy, Antwerp, Belgium
Passage (NWP), and the Transpolar Sea Route (TSR) [3]. Every year, the NSR is ice-free for about three months [4]. The NSR and NWP offer a shorter shipping distance between Asia and the European continent, and between Asia and the North American continent, respectively, in comparison with the current routes through the Suez and Panama Canals [5]. The shorter shipping distance brought by the Arctic route potentially brings value to global supply chains by reducing lead times, particularly for container shipping [6]. Shortening the sailing distance by about $40 \%$ [7] can reduce the shipment time by 7-14 days, when compared with the Suez Canal Route [8].

Other estimated benefits of using these routes include cost savings in vessel operations [9], reduction of ship emissions [10], future navigability [11] and increased access to regional resources [12]. However, when considering yearround operations, the NSR and/or the NWP are shown to be uncompetitive in most studies, especially for liner shipping, as reported in five out of nine studies reported in the literature review by Theocharis et al. [13], with an additional four studies showing mixed results, see e.g., Verny and Grigentin [14], Liu and Kronbak [15], Lasserre [16], Wang et al. [6]. The cost competitiveness of the Arctic routes is slightly better when considering a seasonal navigation period or single voyages, although the results are very dependent on the scenarios used and the considered origin-destination pairs (see 
e.g., Lasserre [16]). For example, Guy [17] found that the NWP is more competitive by $4.3-32.5 \%$ for liner shipping than the Suez Canal route under a set of optimistic scenarios.

As of 2019 , container shipping accounts for $52 \%$ of the global seaborne trade [18]. The diversity in the types of commodities transported provides a unique advantage for the container shipping business [19] in view of penetrating new shipping routes and adopt innovative business models. The development of container services on the NSR potentially increases the routing options available to cargo owners on the Europe-Far East trade route. Such development complements other emerging maritime and land-based routing alternatives to the Suez Canal Route (SCR), such as the emerging south-south route via the Cape Good Hope in southern Africa [20] and the development of rail-based inland container services between China and Europe in the context of the Belt and Road Initiative (BRI) of the Chinese government [21]. Using a bootstrapped multinomial logit model, Zeng et al. [22] explored the competitiveness of the NSR compared to the SCR and China-Europe rail services under varying development trends related to economic conditions, natural conditions, and shippers' preferences. Their findings show that, while the NSR is the most attractive for the Northeast Asian region, its overall market share remains low even when considering low competition levels with other routing options.

Despite existing doubts about the commercial viability of container shipping using the Arctic routes, its development is supported by a growing interest from non-Arctic countries [23], particularly China, a country with a large container fleet and responsible for a large portion of global container shipping demand [24]. Major global players are exploring the potential offered by the Arctic routes. Shipping companies have already used both the NSR and NWP experimentally and commercially [25], with a main focus on bulk shipping. Still, in June 2019, liner shipping company A.P. Moller-Maersk announced that they are working in collaboration with Atomflot - a Russian operator of nuclear-powered icebreakers, to explore possibilities at the NSR [26]. Earlier, in September 2018, the company operated the container ship 'Venta Maersk' with a unit capacity of some 3600 TEU through this route. However, major shipping lines including Maersk have not yet scheduled any liner shipping services through the NSR as the NSR is currently not seen as a viable commercial alternative to existing east-west routes. Some carriers take a very prudent approach to the use of the Arctic route. For example, in August 2019, CMA CGM announced not to allow its ships to sail along the NSR from Europe to Asia. The carrier referred to this decision as a "socially responsible choice" to protect the Arctic and the planet [27].

Meanwhile, interest and investment in autonomous ship technologies have also increased noticeably [28]. The catalyst for this dynamic is a prospective combination of reduced operational costs [29] and increased safety by reduced human involvement [30]. Increased safety [31] and positive environmental impact [32] are two of the primary benefits of autonomous shipping. Interestingly, these are also the two most concerned and contestable issues when it comes to Arctic shipping route evaluation [33]. After several years of discussion, from 1st Jan 2017 the International Maritime Organization (IMO) adopted 'the International Code for Ships Operating in Polar Waters' (widely known as 'Polar Code') to provide appropriate safety and environmental protection standards $[34,35]$. Although this is a historic milestone, still, more initiatives can be taken to ensure safety at the Arctic route [35]. Munim [36] and [37] argue that the use of autonomous ships can contribute to a higher degree of safety at the Arctic route. In addition to operational safety, other aspects of economic, environmental and societal performance may be improved with autonomous ships, compared to conventional shipping operations.

Researchers have investigated the potential of the Arctic route [16], [38], [13] and autonomous shipping [28]. Lasserre [16] and Cariou, Cheaitou, Faury, and Hamdan [39] scrutinised the competitiveness of container shipping in the Arctic route. Meanwhile, to the best of the author's knowledge, no studies exist at the intersection among the three issues, that is, on the evaluation of the benefits of autonomous ships for container shipping in the Arctic route. This paper fills this research gap by evaluating the competitiveness of various autonomous ship alternatives for container shipping in the Arctic route using the Best-Worst Method (BWM).

The paper is structured as follows. In Sect. 2, we identify the major autonomous ship alternatives and the criteria for competitiveness evaluations of autonomous ships for the Arctic route grounding on extant literature. Section 3 presents the methodology and the data collection procedure. The BWM is applied in Sect. 4. We discuss the main findings in Sect. 5 and conclude in Sect. 6.

\section{Identification of criteria and alternatives for autonomous ship operations in the Arctic route}

The first step in the evaluation of the competitiveness of various autonomous ship alternatives for container shipping in the Arctic consists of the identification of autonomous ship alternatives, and relevant criteria that can be used to measure the alternative's competitiveness.

\subsection{Alternatives for autonomous ship operations}

We consider four container ship alternatives for the Arctic shipping route among which three are autonomous with 
varying degree. The IMO [40] has categorised autonomous ships into four categories. The first category includes ships with seafarers having automated decision support systems in place. Both the second and third categories include ships that are remotely controlled from another location, while the latter being without on-board seafarers. The fourth category includes ships that are fully autonomous capable of making decisions by themselves. Previous studies suggested that greater potential for autonomous ships lies in operations without seafarers [41, 42]. Hence, the fully autonomous, and remotely controlled from Shore Control Centre (SCC) semiautonomous ship are worth considering in future applications. In addition, the vessel platooning concept represents another semi-autonomous ship alternative where one lead vessel is followed by multiple vessels connected with each other via sensors [43]. Besides, Munim [36] discusses the potential use of a fully autonomous ship, Shore Control Centre (SCC) controlled semi-autonomous ship and vessel platooning in different contexts including the Arctic.

Consequently, we consider these three autonomous ship alternatives and one conventional ship alternative for the purpose of benchmarking. A ship's capabilities to navigate in ice-infested areas of the high seas are usually subject to evaluation and framing by its classification societies. A classification society is usually appointed by the ship-owner. Ice class is a rating for operability in ice and can be applicable both for conventional ships and autonomous ships. Classification societies are merchant shipping industry's largest resource for regulating the technical and operational standards of ships. Ice classes and their notations vary across the classification societies. In 2007, the Polar Classes were published by the International Association of Classification Societies (IACS) in an attempt to uniformize the various ice classing rules and regulations [44]. In the next sections, we elaborate further on the four chosen ship alternatives.

\subsubsection{Fully autonomous ship}

A fully autonomous ship is a ship which can operate independently without assistance from the shore. The operating system of the ship is able to make decisions and determine actions by itself [40, 42]. The Maritime Unmanned Navigation through Intelligence in Networks (MUNIN) project lead by the Norwegian stakeholders concluded that it is possible to achieve a full degree of automation in ship operations, but a few constraints exist [42]. The constraints include improved sensors and telecommunication technologies than currently used in conventional shipping, the regulatory framework at the national and international level, and cost-effectiveness $[45,46]$. A critical design factor for the execution of ocean shipping with fully autonomous ships is the implementation of more reliable technical systems on-board, compared to what is applied in present conventional ships [45].

\subsubsection{Semi-autonomous ship controlled from shore control centre}

The SCC is a place on the shore, from where an operator can remotely control and oversee a ship [47], that may be unmanned or partially manned with an observatory and/or emergency role. According to the MUNIN project, a SCC operator will be able to monitor more than one ship at a time [42], but the number of ships can vary depending on the reliability of the autonomous system technology [47].

\subsubsection{Vessel platooning}

The vessel platooning or vessel train concept relies on the control of several ships from a lead ship [48], which can be fully manned or SCC controlled and responsible for the navigation, communication and situational awareness [49] of the follower unmanned or reduced manned ships via real-time wireless communication [50]. Meersman et al. [43] argue that vessel platooning is the most suitable alternative for liner shipping services that can reduce operation cost significantly, particularly for short sea shipping (SSS) and inland river transportation.

\subsubsection{Conventional ship}

For the purpose of benchmarking the autonomous ship alternatives, we consider the conventional ship as a fourth alternative. Conventional ships are manned and operated by seafarers (deck and engine). Navigational decisions are taken onboard by the Captain, supported by senior officers (first and second mates). However, these decision-making processes are facilitated and supported by a range of onboard technologies such as radars, gyro and magnetic compasses, autopilot systems, speed and distance log devices, Electronic Chart Display Information System (ECDIS), Automatic Identification System (AIS) and other aids to optimize vessel movements (e.g., to reduce squat), vessel routing and fuel consumption.

\subsection{Competitiveness criteria}

Based on a review of existing literature and discussion with experts, we identify eight key criteria for evaluating the competitiveness of autonomous ship categories for the Arctic shipping route. Table 1 presents the list of eight criteria, their description and references to relevant literature. 


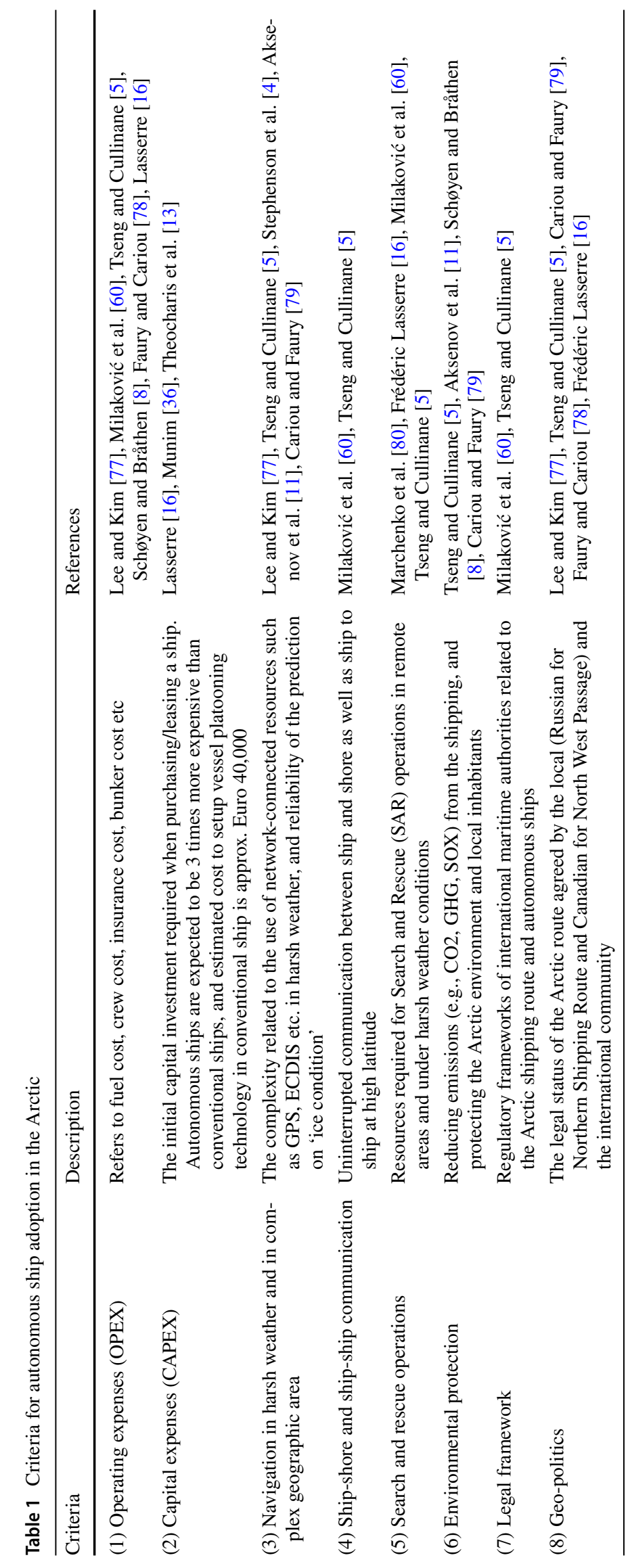




\subsubsection{Operating expenses (OPEX)}

Operating expenses are the majority of a shipping company's expenses, typically ranging between 40 and $60 \%$ of all expenses. Voyage and crew costs make up the largest portion of the overall operating expenses for conventional ships. Changes in fuel grade and rate of consumption impact voyage cost [16]. Due to regulatory [51] and technical [16] requirements of using higher grade of fuel in the Arctic area, the savings on fuel cost may not be significant when using the Arctic route. At higher latitude, travel time and fuel consumption can increase [52]. Hence, ship owners may choose different fuel alternatives such as LPG or LNG. Additional costs, such as icebreaker escort/transit fees [13, 39], can reduce the cost savings of having a shorter sailing distance. Further, an ice-class ship incurs an estimated $9 \%$ increase in shipping cost in comparison to a conventional ship which requires ice-breaker assistance to navigate through sea ice [53]. Meanwhile, manning expenditures, which are about $33-50 \%$ of the operational cost [54], can be eliminated by unmanned operation of ships, although additional labour costs might be incurred ashore in case of remotely operated vessel operations.

\subsubsection{Capital expenses (CAPEX)}

For a shipping company, capital expenses make up the second largest portion of total expenses after operating expenses. Both shipping in the Arctic and autonomous ships involve additional capital expenses compare to conventional shipping. Generally, year-long navigability is essential for offering a reliable liner shipping service via the Arctic route. Currently, for the periods other than August to October, and maybe in the future during periods other than June to November, ice class ships higher than PC5 are required for the Arctic route [52]. This means the capital expenses for an ice class ship are substantially higher than for a conventional ship in regular shipping routes. Furthermore, the newbuilding price for autonomous ships is likely to be three times higher than conventional ships [36, 55], although this can vary greatly depending on the technical and structural features, future technological advances and the overall evolution in the technology cost curve. Considering the current state of development, an autonomous ship can yield higher profit in a 25-years of life expectancy due to reduced operating expenses [41].

\subsubsection{Navigation in harsh weather and complex geographic area}

Navigation in the Arctic involves more complexity than conventional shipping. As identified by Aksenov et al. [11], 'sea ice condition' is and will be one of the key issues for navigation and ship safety in the Arctic route until 2030. Reliability of the prediction of the 'ice condition' may limit navigability [56]. Ice, weather, fog, storm [3], six months of darkness during the polar night [57] and remoteness [58] impose extreme precaution for an independent voyage through the Arctic route. Meanwhile, surveillance-based collision-avoidance functionality of autonomous ships should ensure reliable and safe navigation [59].

\subsubsection{Ship-shore and ship-ship communication}

For a well-functioning transportation system in the Arctic involving autonomous ships, smooth ship-shore communication (such as ports, SCC, etc.) and ship-ship communication must be ensured. The use of network-connected resources such as GPS, ECDIS, etc. in harsh weather is a challenge. Geostationary satellite experience reduced reliability after passing $72^{\circ} \mathrm{N}$ latitude and is considered unreliable after $75^{\circ} \mathrm{N}$ latitude [60]. Despite efforts from the local authorities to extend the reliability of satellite services [60], there still are serious limitations [3] and real risks of losing satellite communication at higher latitude [60]. As wireless communication systems are critical components for any unmanned ship or remote operation [37], any serious risk in terms of unstable or broken communication negatively impact the competitiveness of autonomous ships for the Arctic route. For instance, through a simulation experiment, Höyhtyä and Martio [46] show that a delay of more than $3 \mathrm{~s}$ in AIS-based situational awareness data transmission between ship and shore and ship to ship can lead to less than $100 \mathrm{~m}$ distance between ships increasing the chance of collision. The best approach to ensure smooth communication for autonomous ships would be to use a hybrid approach by integrating multiple radio frequency technologies such as $6 \mathrm{G}$ system, very high frequency (VHF) and digital high frequency (DHF) etc. $[45,46]$. Morveover, geostationary satellite orbit (GSO) satellites are needed to ensure long-range communication services in all ocean areas. Low earth orbit (LEO) and Highly lliptical orbit (HEO) satellites are particularly essential for the Arctic regions [45, 46].

\subsubsection{Search and rescue operations (SAR)}

There are several requirements from the IMO and European Union (EU) on life-saving appliances for a ship to navigate through the Arctic route [61]. Limitation on resources for the search and rescue operations (SAR) in remote areas and harsh weather makes the ship operations more difficult and costly [62]. Autonomous ships can reduce some of the risks associated with shipping in the Arctic route [36] and can further reduce the challenges on SAR by eliminating human involvement. Studies predict that autonomous ships can reduce fatalities [42] and likelihood of collision [63]. 


\subsubsection{Environmental protection}

For arctic shipping, it is essential to ensure the environmental protection of the region. From a ship operations perspective, a lower vessel speed leading to lower fuel consumption is likely to reduce exhaust emissions during an Arctic voyage $[52,56]$. This also supports IMO's goal of reducing GHG emission from shipping at least 50\% below 2008 levels by 2050 [64]. On the other hand, although Arctic transit is likely to save time and fuel, it might accelerate Arctic warming [11]. The protection of the Arctic nature and living environment of the local inhabitants is also important [65]. Quoting the Canadian minister Dominic LeBlanc, [23] stated that"... any activities in the Arctic have to ensure that the exploring and exploiting of the Arctic environment is happening in an environmental friendly way...' (p. 477). Technological advancement can ensure minimal emissions in the Arctic. For example, Kongsberg-Maritime [66] promises zero-emission from their electric autonomous ship prototype. Allal et al. [67] found that an electric autonomous ship can reduce energy consumption by $74 \%$ in comparison to a conventional ship operating on heavy fuel oil, as a result of the combined effect of the use of a different energy source, the elimination of the deckhouse on board (no crew) and no ballast ship design. Furthermore, the development of wind propulsion technologies and alternative fuels such as hydrogen might further reduce the environmental impact of Arctic shipping.

\subsubsection{Legal framework}

The sustainable growth of the Arctic route requires an established and supportive governance system [65]. Chircop [68] conclude that regional cooperation, inclusion of non-Arctic states in shipping governance, and a uniform set of rules and standards for ship safety and marine environmental protection are needed ( $p$. 355). The adaptation of the Polar code within both SOLAS and MARPOL [35] can bring Arctic shipping under the existing global frameworks. The Maritime Safety Committee (MSC) of the IMO is working to develop a regulatory framework for Maritime Autonomous Surface Ship (MASS) [69].

\subsubsection{Geo-politics}

Geo-politics can play an important role when evaluating the Arctic shipping route. Different stances among flag and port state nations linked to autonomous ships and Arctic shipping may lead to conflicts, for example, disparities in societal demands between flag and port states if they were to accommodate unmanned ships. Among the Arctic nations, Russia and Canada argue for their national jurisdictions along the NSR and NWP, respectively [65]. The USA, Norway and Denmark also demonstrate their interest over the Arctic region [5]. Currently, only Russian icebreakers are allowed through the NSR for assistance or escort services [60]. Therefore, we consider that geo-politics criteria might affect various shipping concepts in different manners.

\section{Methodology}

\subsection{Motivation behind the use of the Best-Worst Method}

In the previous section, we have identified relevant autonomous ship alternatives, and criteria that can be used to measure the alternatives' competitiveness in the context of container shipping in the Arctic. Some of the criteria are quantitative in nature (such as ship costs) while other are highly qualitative and far more difficult to measure (such as geopolitics and legal framework). Given this combination of rather heterogenous criteria, we present a high-level comparison of the competitiveness of the four autonomous ship alternatives using multiple-criteria decision-making (MCDM). MCDM includes a large family of quantitative methods that utilize multiple criteria for decision-making. One of the recently developed MCDM methods is the Best-Worst Method (BWM) proposed by Rezaei [70]. The BWM has been employed to evaluate the competitiveness of each of the ship alternatives using the set of identified criteria. BWM has several benefits over conventional MCDM methods such as Analytical Network Process (ANP) or Analytical Hierarchy Process (AHP). The unique structure of BWM reduces the number of required pairwise comparisons significantly in comparison to ANP or AHP. This ensures higher consistency in pairwise comparisons of criteria which is often difficult to achieve in traditional MCDM methods. Thus, MCDM studies in various research areas have applied BWM, e.g. in view of sustainability evaluation of supply chains [71], airline baggage handling quality assessment [30], governance model evaluation for green port management [72] etc. Similar to other BWM studies, we apply the method in the six steps: (1) Formulation of the problem; (2) Find the best and the worst criterion; (3) Find the preference of the best criterion over all other criteria; (4) Find the preference of all other criteria over the worst criterion; (5) Estimate optimal weights; and (6) Final scores of alternatives.

\subsection{Data collection}

The data needed to apply BWM was collected through the purposive sampling approach. We identified potentially relevant respondents based on their extensive expertise in the field of Arctic shipping, autonomous ship technology and operations, container shipping or a combination of two or 
Table 2 Overview of respondents

\begin{tabular}{llllll}
\hline Res & Expertise & Country & Affiliation & Exp. (years) & Education \\
\hline 1 & Maritime supply chain & Australia & Academic & 7 & PhD \\
2 & Arctic shipping & Canada & Industry-commercial & 5 & Masters \\
3 & Maritime supply chain & Canada & Industry-research & 15 & Masters \\
4 & Marine technology & Norway & Industry-technical & 26 & Masters \\
5 & Information technology & Norway & Industry-research & 10 & Masters \\
6 & Ship design & Norway & Academic & 10 & PhD \\
7 & Marine technology & Norway & Academic & 5 & PhD \\
8 & Marine technology & Norway & Academic & 15 & Masters \\
9 & Digitalization and autono- & Norway & Industry-research & 12 & Masters \\
& mous control & & & & \\
10 & Ship management & Norway & Industry-technical & 30 & Masters \\
11 & Shipping advisory & Norway & Industry-technical & 30 & Masters \\
12 & Marine technology & Norway & Academic & 10 & PhD \\
13 & Arctic shipping & Norway & Industry-research & 14 & Masters \\
14 & Arctic shipping & France & Academic & 08 & PhD \\
15 & Ship design & Finland & Academic & 05 & PhD \\
16 & Maritime supply chain & Norway & Industry-commercial & 18 & Masters \\
\hline
\end{tabular}

all of these areas. We sent the BWM survey, different and rather complex than typical questionnaire surveys, to 58 relevant respondents via email (19) and LinkedIn (39). Before distributing the survey among respondents, we sent pilot surveys to three experts, which were later on removed from the main analysis. Based on their feedback, some of the survey questions were adjusted for better clarity. Before distributing the survey, we have checked the survey to meet ethical approval requirements, ${ }^{1}$ but this process did not reveal any issues as we did not collect any directly or indirectly identifiable personal data of the respondents.

Data was collected in two-phases. Initially, we received 13 responses during August-September 2019. Two responses were dropped due to straight lining. Out of the remaining 11, three responses were dropped due to incompleteness leaving eight observations for analysis. A second round of data collection was conducted during March-April 2021 adding eight observations. Table 2 presents the demographic detail of the 16 respondents. Most of the published MCDM studies use between 4 to 10 observations [73] as data saturation can be achieved. MCDM methods are analytical methods without statistical inference. In analytical methods, the quality of the information or observations is more important than the quantity. Hence, a sample of sixteen highly relevant and qualified respondents can generate reliable findings. For robustness checks, Fig. 2 reports the sensitivity analysis of findings in relation to the number of observations.

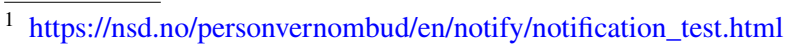

\section{Empirical application of the BWM}

We empirically apply BWM to autonomous shipping in the Arctic by following six steps.

\subsection{STEP 1 Formulation of the problem}

The first step is to determine the evaluation criteria for decision making about the autonomous ship alternatives. As mentioned earlier, we consider three autonomous ship categories and one conventional alternative to benchmark. As discussed in Sect. 2.1, the four alternatives are: fully autonomous ship, semi-autonomous vessel controlled from SCC, vessel platooning and conventional ship. We consider eight criteria associated with the adaptation of autonomous ships in the Arctic (see Sect. 2.2), i.e., operating expenses $\left(c_{1}\right)$, capital expenses $\left(c_{2}\right)$, navigation in harsh weather and complex geographic area $\left(c_{3}\right)$, ship-shore and ship-ship communication $\left(c_{4}\right)$, search and rescue operations $\left(c_{5}\right)$, environmental protection $\left(c_{6}\right)$, legal framework $\left(c_{7}\right)$ and geo-politics $\left(c_{8}\right)$.

\subsection{STEP 2 Find the best and the worst criterion}

In step 2, we asked the respondents, "which of the eight criteria is the most important for shipping in the Arctic route?" and "which of the eight criteria is the least important for shipping in the Arctic route?". We refer to the most important criterion as the best and the least important criterion as the worst. Out of the eight respondents, three said that 
Table 3 Best to others vector

\begin{tabular}{llllllllll}
\hline Respondent & Best & OE & CE & NV & SC & SR & EP & LF & GP \\
\hline 1 & GP & 5 & 2 & 9 & 8 & 8 & 9 & 9 & 1 \\
2 & NV & 6 & 7 & 1 & 6 & 5 & 4 & 4 & 7 \\
3 & OE & 1 & 5 & 1 & 3 & 4 & 5 & 5 & 2 \\
4 & SR & 6 & 4 & 5 & 5 & 1 & 5 & 4 & 4 \\
5 & OE & 1 & 4 & 6 & 6 & 2 & 8 & 8 & 6 \\
6 & EP & 4 & 4 & 2 & 3 & 1 & 1 & 4 & 4 \\
7 & EP & 5 & 3 & 1 & 2 & 5 & 1 & 3 & 6 \\
8 & OE & 1 & 2 & 3 & 5 & 3 & 2 & 4 & 4 \\
9 & CE & 2 & 1 & 5 & 5 & 7 & 1 & 5 & 1 \\
10 & OE & 1 & 2 & 2 & 7 & 3 & 7 & 9 & 9 \\
11 & OE & 1 & 5 & 8 & 8 & 8 & 8 & 8 & 8 \\
12 & NV & 3 & 3 & 1 & 7 & 2 & 6 & 3 & 3 \\
13 & EP & 7 & 7 & 8 & 3 & 3 & 1 & 3 & 3 \\
14 & OE & 1 & 1 & 1 & 8 & 4 & 1 & 1 & 8 \\
15 & OE & 1 & 1 & 3 & 2 & 2 & 2 & 3 & 2 \\
16 & LF & 1 & 2 & 3 & 2 & 2 & 3 & 1 & 3 \\
\hline
\end{tabular}

1 indicates equal importance and 9 indicates absolutely more important

OE operating expenses, $C E$ capital expenses, $N V$ navigation in harsh weather and complex geographic area, $S C$ ship-shore and ship-ship communication, $S R$ search and rescue operations, $E P$ environmental protection, $L F$ legal framework, $G P$ geo-politics

Table 4 Others to worst vector

\begin{tabular}{llllllllll}
\hline Respondent & Worst & OE & CE & NV & SC & SR & EP & LF & GP \\
\hline 1 & II & 7 & 1 & 2 & 2 & 2 & 2 & 2 & 2 \\
2 & LF & 7 & 6 & 7 & 6 & 5 & 6 & 1 & 6 \\
3 & LF & 9 & 1 & 9 & 5 & 4 & 2 & 1 & 6 \\
4 & NV & 7 & 7 & 1 & 4 & 8 & 8 & 7 & 7 \\
5 & SR & 8 & 6 & 7 & 6 & 1 & 8 & 8 & 6 \\
6 & LF & 5 & 5 & 7 & 6 & 8 & 8 & 1 & 5 \\
7 & GP & 2 & 4 & 6 & 5 & 2 & 6 & 4 & 1 \\
8 & SC & 8 & 7 & 6 & 1 & 6 & 7 & 5 & 5 \\
9 & SC & 8 & 8 & 5 & 1 & 3 & 8 & 5 & 7 \\
10 & LF & 8 & 2 & 1 & 5 & 4 & 3 & 1 & 2 \\
11 & NV & 8 & 8 & 1 & 8 & 8 & 8 & 8 & 8 \\
12 & SC & 2 & 4 & 9 & 1 & 9 & 7 & 8 & 8 \\
13 & CE & 5 & 1 & 3 & 8 & 8 & 9 & 7 & 7 \\
14 & GP & 8 & 8 & 8 & 8 & 8 & 8 & 8 & 1 \\
15 & NV & 2 & 2 & 1 & 1 & 2 & 2 & 1 & 2 \\
16 & GP & 3 & 2 & 1 & 2 & 2 & 1 & 3 & 1 \\
\hline
\end{tabular}

1 indicates equal importance and 9 indicates absolutely more important

$O E$ operating expenses, $C E$ capital expenses, $N V$ navigation in harsh weather and complex geographic area, $S C$ ship-shore and ship-ship communication, $S R$ search and rescue operations, $E P$ environmental protection, $L F$ legal framework, $G P$ geo-politics

operating expenses are the most important criterion followed by environmental protection (Table 3 ). Three of the eight respondents said that the legal framework is the least important criterion (Table 4).

\subsection{STEP 3 Find the preference of the best criterion over all other criteria}

Table 3 presents the best to others criteria vector. To obtain this, respondents ranked the importance of the best criterion 
over all other criteria using a 1-9 scale. Hence, we can express the best to others vector as:

$A_{B}=\left(a_{b 1}, a_{b 2}, \ldots, a_{b n}\right)$

Here, $a_{b j}$ indicates the preference of the best criterion $B$ over the criterion $j$.

\subsection{STEP 4. Find the preference of all other criteria over the worst criterion}

Table 4 presents the other to worst vector. Respondents ranked the importance of all other criteria over the worst criterion on a scale from 1 to 9 . Hence, we can express the others to worst vector as:

$A_{W}=\left(a_{1 w}, a_{2 w}, \ldots, a_{n w}\right)$

Here, $a_{j w}$ indicates the preference of the criterion $j$ over the worst criterion $W$.

\subsection{STEP 5 Estimate optimal weights}

In this stage, we minimize the maximum absolute differences $\left(\left|w_{\mathrm{b}}-a_{\mathrm{bj}} w_{\mathrm{j}}\right|,\left|w_{\mathrm{j}}-a_{\mathrm{jw}} w_{\mathrm{w}}\right|\right)$ for all $j$ to find the optimal weights of a criterion. Following Rezaei [70], we can express the minimization problem as:

$$
\begin{aligned}
& \min \left[\max _{j}\left(\left|w_{b}-a_{b j} w_{j}\right|,\left|w_{j}-a_{j w} w_{w}\right|\right)\right] \\
& \text { s.t. } \sum_{j} w_{j}=1 \\
& \quad w_{j} \geq 0, \text { for all } j
\end{aligned}
$$

Again, following Rezaei [70], we can solve (3) as a liner optimization model shown in (4).

$\min \delta^{\mathrm{L}}$

$$
\begin{gathered}
\min \delta^{\mathrm{L}} \\
\text { s.t. } \\
\left|w_{\mathrm{b}}-a_{\mathrm{bj}} w_{\mathrm{j}}\right| \leq \delta^{\mathrm{L}}, \text { for all } \mathrm{j} \\
\left|w_{\mathrm{j}}-a_{\mathrm{jw}} w_{\mathrm{w}}\right| \leq \delta^{\mathrm{L}}, \text { for all } \mathrm{j} \\
\sum_{j} w_{j}=1 \\
w_{j} \geq 0, \quad \text { for all } j
\end{gathered}
$$

A solution to (4) gives the optimal weights $\left(w_{1}{ }^{*}, w_{2}{ }^{*}, \ldots, w_{\mathrm{n}}{ }^{*}\right)$ as well as the optimal value of $\delta^{\mathrm{L}} . \delta^{\mathrm{L}^{*}}$ is the consistency ratio of the pair-wise comparison procedure in BWM. For solving (4), we use the BWM Excel solver (http://bestworstmethod.com/software/). We present the optimal weights of each of the criteria and consistency ratio $\delta^{\mathrm{L} *}$ of each respondent in Table 5. As the consistency ratio in BWM is output-based, a $\delta^{\mathrm{L} *}$ up to 0.459 is acceptable for studies with eight criteria [74]. In this study, the average consistency ratio is 0.122 , and none of the individual consistence values exceeded the maximum threshold.

\subsection{STEP 6 Final scores of alternatives}

To calculate the final priority of ship alternatives for the Arctic shipping route, we need the competitiveness scores for each of the four ship alternatives. Respondents were asked to rate the competitiveness level of the four alternatives under each of the eight criteria using a 1-9 scale, where 1 refers to 'extremely competitive' and 9 refers to 'not competitive at all'. Table 6 presents the responses from the 8 th respondent as an example. We normalized the values in Table 6 by dividing each value by their column-wise maximum value, a linear normalization approach $\left(x_{\mathrm{ij}}^{\mathrm{norm}}=\frac{x_{\mathrm{ij}}}{x_{\mathrm{j}}^{\mathrm{max}}}\right)$. Table 7 presents the normalized values for the 8 th respondent.

To calculate the priority of the four ship categories of the 8th respondent, first, we multiply each of the normalized values in Table 7 by their respective weights. In the final stage, we take the row-wise total and get the final priority scores of each of the ship alternatives (Table 8). We can express this process as follows:

$Z_{\mathrm{i}}=\sum_{\mathrm{j}=1}^{\mathrm{n}} w_{\mathrm{j}} x_{\mathrm{ij}}^{\mathrm{norm}}$

Here, $Z_{i}$ is the final priority value of the alternative $i$ and $x_{\mathrm{ij}}^{\text {norm }}$ denotes the normalized values of the criterion $j$ under the alternative $i$.

By repeating the same calculation process demonstrated in Tables 6-8, we can calculate the priorities for the ship categories for all respondents, which we present in Table 9. Overall, the conventional ship (the benchmark) is the most preferred for Arctic shipping, followed by semi-autonomous ships, vessel platooning and then fully autonomous ship. This indicates that the semi-autonomous ship controlled via SCC will be a viable alternative for Arctic shipping in the near future.

Earlier in Table 8, we presented the priority score of each autonomous ship alternative under each of the criteria for respondent 8 . To find the aggregate priorities, we calculate the average of all respondents (Table 10). The conventional ship alternative achieves the highest priority on the majority of the criteria including capital expenses, navigation in harsh weather and complex geographic area, search and rescue operations, environmental protection, legal framework and geo-politics. The fully autonomous 
Table 5 Optimal weights (full sample)
Table 6 Competitiveness of ship category under each criterion (Respondent 8 example)

\begin{tabular}{llllllllll}
\hline Respondent & OE & CE & NV & SC & SR & EP & LF & GP & $\delta^{L *}$ \\
\hline 1 & 0.137 & 0.060 & 0.076 & 0.086 & 0.086 & 0.076 & 0.076 & $\mathbf{0 . 4 0 3}$ & 0.283 \\
2 & 0.093 & 0.080 & $\mathbf{0 . 3 6 2}$ & 0.093 & 0.112 & 0.140 & 0.041 & 0.080 & 0.196 \\
3 & 0.231 & 0.033 & $\mathbf{0 . 2 9 7}$ & 0.099 & 0.074 & 0.059 & 0.059 & 0.148 & 0.066 \\
4 & 0.081 & 0.122 & 0.033 & 0.098 & $\mathbf{0 . 3 2 5}$ & 0.098 & 0.122 & 0.122 & 0.162 \\
5 & $\mathbf{0 . 3 4 7}$ & 0.153 & 0.102 & 0.102 & 0.042 & 0.076 & 0.076 & 0.102 & 0.263 \\
6 & 0.074 & 0.074 & 0.147 & 0.098 & 0.209 & $\mathbf{0 . 2 9 4}$ & 0.031 & 0.074 & 0.086 \\
7 & 0.059 & 0.098 & $\mathbf{0 . 2 5 2}$ & 0.147 & 0.059 & $\mathbf{0 . 2 5 2}$ & 0.098 & 0.035 & 0.042 \\
8 & $\mathbf{0 . 2 4 8}$ & 0.166 & 0.111 & 0.033 & 0.111 & 0.166 & 0.083 & 0.083 & 0.085 \\
9 & 0.132 & 0.194 & 0.053 & 0.025 & 0.038 & $\mathbf{0 . 2 6 4}$ & 0.053 & 0.243 & 0.070 \\
10 & $\mathbf{0 . 2 9 5}$ & 0.243 & 0.052 & 0.069 & 0.162 & 0.069 & 0.054 & 0.054 & 0.191 \\
11 & $\mathbf{0 . 4 4 7}$ & 0.126 & 0.033 & 0.079 & 0.079 & 0.079 & 0.079 & 0.079 & 0.184 \\
12 & 0.120 & 0.120 & $\mathbf{0 . 2 5 9}$ & 0.023 & 0.179 & 0.060 & 0.120 & 0.120 & 0.100 \\
13 & 0.059 & 0.030 & 0.051 & 0.137 & 0.137 & $\mathbf{0 . 3 1 0}$ & 0.137 & 0.137 & 0.102 \\
14 & $\mathbf{0 . 1 7 8}$ & $\mathbf{0 . 1 7 8}$ & $\mathbf{0 . 1 7 8}$ & 0.031 & 0.063 & $\mathbf{0 . 1 7 8}$ & $\mathbf{0 . 1 7 8}$ & 0.013 & 0.073 \\
15 & $\mathbf{0 . 1 9 2}$ & $\mathbf{0 . 1 9 2}$ & 0.077 & 0.115 & 0.115 & 0.115 & 0.077 & 0.115 & 0.038 \\
16 & $\mathbf{0 . 2 1 5}$ & 0.116 & 0.066 & 0.116 & 0.116 & 0.077 & $\mathbf{0 . 2 1 5}$ & 0.077 & 0.017 \\
Mean & $\mathbf{0 . 1 8 2}$ & 0.124 & 0.134 & 0.084 & 0.119 & 0.145 & 0.094 & 0.118 & 0.122 \\
\hline
\end{tabular}

Bold indicates highest weight for the respective respondent

$O E$ operating expenses, $C E$ capital expenses, $N V$ navigation in harsh weather and complex geographic area, $S C$ ship-shore and ship-ship communication, $S R$ search and rescue operations, $E P$ environmental protection, $L F$ legal framework, GP geo-politics

\begin{tabular}{lllllllll}
\hline Ship category & OE & CE & NV & SC & SR & EP & LF & GP \\
\hline Fully autonomous & 6 & 6 & 3 & 8 & 8 & 3 & 3 & 3 \\
Semi-autonomous & 6 & 6 & 3 & 7 & 3 & 3 & 3 & 3 \\
Vessel platooning & 5 & 5 & 3 & 7 & 3 & 3 & 3 & 3 \\
Conventional ship & 3 & 3 & 3 & 3 & 3 & 3 & 3 & 3
\end{tabular}

$O E$ operating expenses, $C E$ capital expenses, $N V$ navigation in harsh weather and complex geographic area, $S C$ ship-shore and ship-ship communication, $S R$ search and rescue operations, $E P$ environmental protection, $L F$ legal framework, $G P$ geo-politics

\begin{tabular}{lllllllll}
\hline Ship category & OE & CE & NV & SC & SR & EP & LF & GP \\
\hline Weights & 0.248 & 0.166 & 0.111 & 0.033 & 0.111 & 0.166 & 0.083 & 0.083 \\
Fully autonomous & 1.000 & 1.000 & 1.000 & 1.000 & 1.000 & 1.000 & 1.000 & 1.000 \\
Semi-autonomous & 1.000 & 1.000 & 1.000 & 0.875 & 0.375 & 1.000 & 1.000 & 1.000 \\
Vessel platooning & 0.833 & 0.833 & 1.000 & 0.875 & 0.375 & 1.000 & 1.000 & 1.000 \\
Conventional ship & 0.500 & 0.500 & 1.000 & 0.375 & 0.375 & 1.000 & 1.000 & 1.000 \\
\hline
\end{tabular}

$O E$ operating expenses, $C E$ capital expenses, $N V$ navigation in harsh weather and complex geographic area, $S C$ ship-shore and ship-ship communication, $S R$ search and rescue operations, $E P$ environmental protection, $L F$ legal framework, $G P$ geo-politics
Table 7 Normalized values (Respondent 8 example) ship alternative is prioritized under the ship-shore and ship-ship communication criteria. Meanwhile, the semiautonomous ship alternative gets the highest priority for operating expenses and second highest for several criteria such as capital expenses, navigation is harsh weather and complex geographic area, ship-shore and ship-ship communication, search and rescue, and environmental protection. Interestingly, the vessel platooning alternative is 
Table 8 Priority of alternatives (Respondent 8 example)

\begin{tabular}{llllllllll}
\hline Ship category & OE & CE & NV & SC & SR & EP & LF & GP & Sum \\
\hline Fully autonomous & 0.248 & 0.166 & 0.111 & 0.033 & 0.111 & 0.166 & 0.166 & 0.166 & $\mathbf{1 . 1 6 6}$ \\
Semi-autonomous & 0.248 & 0.166 & 0.111 & 0.029 & 0.042 & 0.166 & 0.166 & 0.166 & $\mathbf{1 . 0 9 3}$ \\
Vessel platooning & 0.206 & 0.138 & 0.111 & 0.029 & 0.042 & 0.166 & 0.166 & 0.166 & $\mathbf{1 . 0 2 4}$ \\
Conventional ship & 0.124 & 0.083 & 0.111 & 0.012 & 0.042 & 0.166 & 0.166 & 0.166 & $\mathbf{0 . 8 7 0}$ \\
\hline
\end{tabular}

Bold indicates priority scores of ship alternatives

$O E$ operating expenses, $C E$ capital expenses, $N V$ navigation in harsh weather and complex geographic area, $S C$ ship-shore and ship-ship communication, $S R$ search and rescue operations, $E P$ environmental protection, $L F$ legal framework, $G P$ geo-politics
Table 9 Priorities for ship categories (full sample)

\begin{tabular}{lllll}
\hline Respondent & $\begin{array}{l}\text { Fully } \\
\text { autono- } \\
\text { mous }\end{array}$ & $\begin{array}{l}\text { Semi- } \\
\text { autono- } \\
\text { mous }\end{array}$ & Vessel platooning & $\begin{array}{l}\text { Conven- } \\
\text { tional } \\
\text { ship }\end{array}$ \\
\hline 1 & 0.561 & $\mathbf{0 . 6 0 4}$ & 0.569 & 0.531 \\
2 & 1.062 & $\mathbf{1 . 1 1 5}$ & 1.018 & 0.980 \\
3 & 0.640 & 0.666 & 0.726 & $\mathbf{0 . 7 9 7}$ \\
4 & 0.665 & $\mathbf{0 . 8 9 1}$ & 0.555 & 0.801 \\
5 & 0.837 & $\mathbf{0 . 8 4 9}$ & 0.810 & 0.891 \\
6 & 0.300 & 0.478 & 0.942 & $\mathbf{1 . 4 7 2}$ \\
7 & 0.920 & 1.045 & 1.092 & $\mathbf{1 . 3 3 0}$ \\
8 & $\mathbf{1 . 1 6 6}$ & 1.093 & 1.024 & 0.870 \\
9 & 0.683 & $\mathbf{1 . 1 3 5}$ & 1.056 & 1.106 \\
10 & 0.298 & 0.593 & 0.394 & $\mathbf{1 . 0 3 1}$ \\
11 & $\mathbf{0 . 8 8 7}$ & 0.743 & 0.771 & 0.609 \\
12 & 0.444 & 0.689 & 0.331 & $\mathbf{0 . 8 0 0}$ \\
13 & 0.875 & 0.872 & 1.029 & $\mathbf{1 . 1 0 8}$ \\
14 & 1.093 & $\mathbf{1 . 1 3 4}$ & 1.165 & 1.121 \\
15 & 0.473 & 0.538 & 0.802 & $\mathbf{1 . 0 2 6}$ \\
16 & $\mathbf{0 . 5 9 5}$ & 0.559 & 0.420 & 0.482 \\
Mean & 0.719 & 0.813 & 0.794 & $\mathbf{0 . 9 3 5}$ \\
\hline
\end{tabular}

Bold indicates highest priority for the respective respondent

not most prioritized for any of the eight criteria, but it achieves the second-highest priority for a number of criteria including environmental protection, legal framework and geo-politics.
For robustness check of the findings, first, we estimated the results using vector normalization instead of linear normalization in STEP 6. Vector normalization can be expressed as follow:

$$
x_{\mathrm{ij}}^{\mathrm{vnorm}}=\frac{x_{\mathrm{ij}}}{\sqrt{\sum_{\mathrm{i}=1}^{\mathrm{m}} x_{\mathrm{ij}}^{2}}}
$$

Here, $x_{\mathrm{ij}}^{\text {norm }}$ denotes the vector normalized values of the criterion $j$ under the alternative $i$, and $m$ denotes the number of alternatives under each criterion $j$. Following the same approach as in Eq. (5), the final priorities of autonomous ship alternatives are calculated. Figure 1 contrasts the priority of ship alternatives estimated using (Fig. 1a) vector and (Fig. 1b) linear normalization. Both approaches generate the same ranking of priorities demonstrating the robustness of the findings.

Further, we conducted a sensitivity analysis of the priority of ship alternatives for both the linear and vector normalization approach as reported in Fig. 2. We present the priority of ship alternatives starting with the aggregate analysis of eight observations, then increasing aggregation level by two observations until the full sample of sixteen observations is aggregated. For both vector and linear normalization approaches, the priorities remain the same under varying degree of aggregation. The conventional ship as benchmark remains the most preferred and the SCC controlled semiautonomous remains the most preferred among the autonomous alternatives under all scenarios.
Table 10 Priority of alternatives under each criterion (full sample aggregate level)

\begin{tabular}{llllllllll}
\hline Ship category & OE & CE & NV & SC & SR & EP & LF & GP & Sum \\
\hline Fully autonomous & 0.144 & 0.075 & 0.091 & $\mathbf{0 . 0 7 1}$ & 0.071 & 0.116 & 0.074 & 0.076 & 0.719 \\
Semi-autonomous & $\mathbf{0 . 1 5 0}$ & 0.093 & 0.106 & 0.068 & 0.081 & 0.121 & 0.095 & 0.099 & 0.813 \\
Vessel platooning & 0.142 & 0.091 & 0.099 & 0.063 & 0.064 & 0.121 & 0.105 & 0.108 & 0.794 \\
Conventional ship & 0.128 & $\mathbf{0 . 1 0 8}$ & $\mathbf{0 . 1 2 4}$ & 0.064 & $\mathbf{0 . 0 9 9}$ & $\mathbf{0 . 1 3 1}$ & $\mathbf{0 . 1 4 1}$ & $\mathbf{0 . 1 3 9}$ & $\mathbf{0 . 9 3 5}$ \\
\hline
\end{tabular}

Bold indicates column-wise highest score

$O E$ operating expenses, CE capital expenses, $N V$ navigation in harsh weather and complex geographic area, $S C$ ship-shore and ship-ship communication, $S R$ search and rescue operations, $E P$ environmental protection, $L F$ legal framework, $G P$ geo-politics 
Fig. 1 Priority of ship alternatives

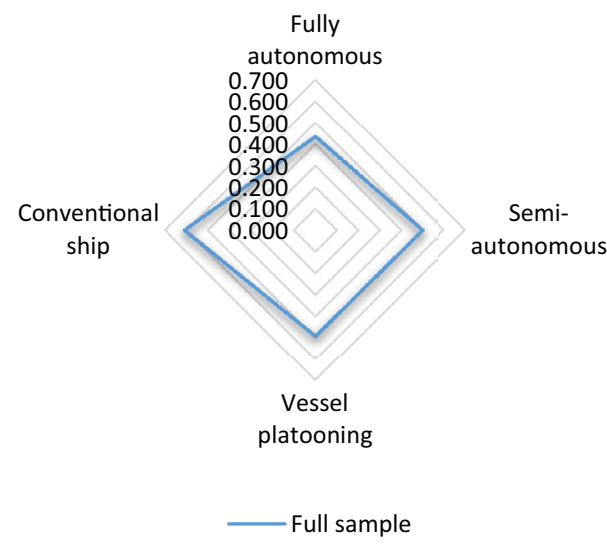

a Vector normalization approach

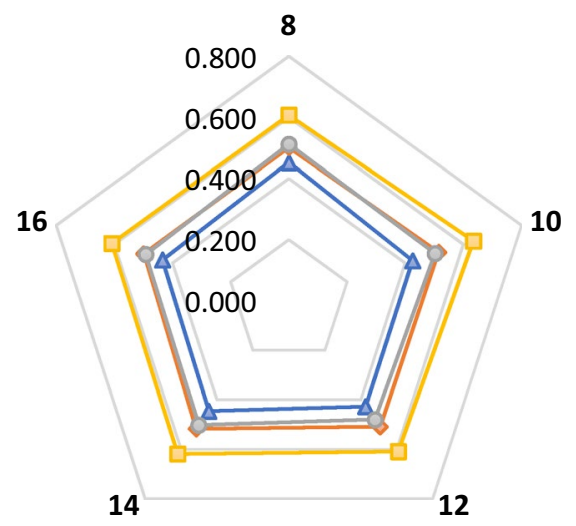

$\longrightarrow$ - Fully autonomous $\multimap$ Semi-autonomous
$\multimap-$ Vessel platooning $\longrightarrow \square-$ Conventional ship

a Vector normalization approach

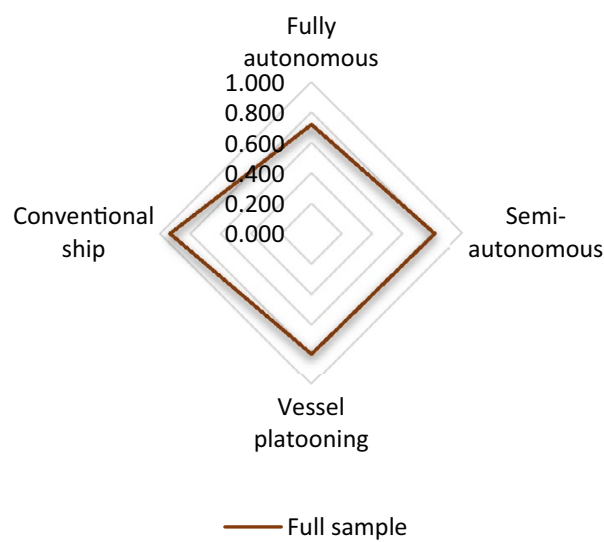

b Linear normalization approach

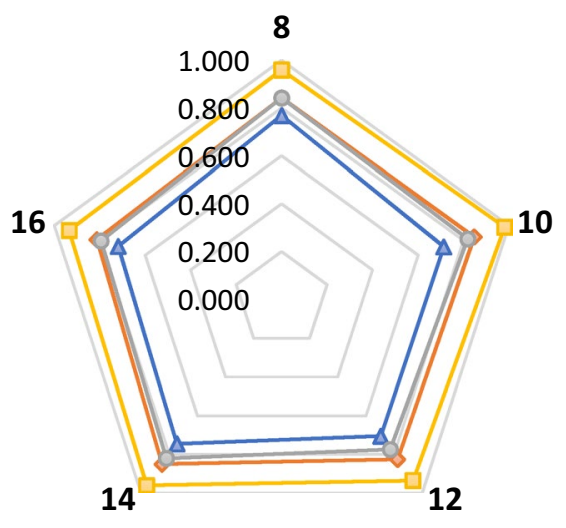

$\triangle$ Fully autonomous $\multimap$ Semi-autonomous

$\multimap-$ Vessel platooning $\square \square-$ Conventional ship

b Linear normalization approach

\section{Discussion}

Based on the findings reported in Sect. 4, the respondents prioritize the conventional container ships (the benchmark) for the Arctic route (mean 0.935). One reason for this could be that although autonomous ship alternative prototypes already exist, their commercial operation is yet to be initiated in the next 5-10 years, hence, more priority for what is already known and operational. The semi-autonomous alternative where the ship is remotely controlled from the SCC is ranked as second prioritized alternative (mean 0.813). Improvement in communication technologies (such as $6 \mathrm{G}$ system, LEO and HEO) and development of dedicated legal frameworks will be key to the deployment of SCC-controlled semi-autonomous ships in the Arctic. The vessel platooning semi-autonomous alternative comes at the third position (mean 0.794). The difference between the priority scores for the two semi-autonomous alternatives is negligible. In fact, from the technical aspects, they can be identical, too. According to Porathe [47], SCC is the remote monitoring and control station of a ship. However, an SCC does not have to be located ashore. It could be located at a place from where the ship can be controlled remotely. From this perspective, the leader-ship in the vessel platooning alternative could play the role of SCC for its follower ships. Thus, vessel platooning with an SCC leader-ship could be a viable alternative for container shipping in the Arctic route as well.

The fully autonomous ship alternative (0.719) is the least prioritized choice. The reasons could be that respondents perceive fully autonomous ships to be too expensive from the capital expense viewpoint, risky for navigation in harsh weather and complex geographic areas, and less feasible 
under environmental protection and legal frameworks (see Table 10). Besides, deploying fully autonomous ships in the Arctic would raise a legal issue as a mandatory provision of manned operation exists under the COLREG (the International Regulations for the Preventing of Collisions at Sea), STCW (the International Convention on Standards of Training, Certification and Watchkeeping for Seafarers), [69] and the Polar code [35]. Furthermore, cybersecurity is a crucial issue for autonomous ships [75] due to the risk of terrorists taking over the control of an autonomous ship [76].

Finally, among the eight competitiveness criteria, the three most important are-operating expenses (0.182), navigation in harsh weather and complex geographic area (0.134), and environmental protection (0.145). Lower operating expenses of autonomous ship alternatives makes them viable for Arctic shipping. With ongoing development in sensor and communication technologies, autonomous ships will soon be able to ensure navigational safety and environmental protection to a degree at least as safe as other conventional shipping routes $[45,46]$.

\section{Conclusion}

This study has provided academia, policymakers, and maritime industry players with new information regarding the potential for further developments and application of autonomous shipping in the Arctic. Based on a literature review, this study presents eight criteria for autonomous ships' adaption in the Arctic. The collection and analysis of primary data from contemporary experts of both Arctic and autonomous shipping, is of great importance to major stakeholders, because some of the challenges and obstacles of Arctic shipping development, in a strategic perspective, is thereby identified. For instance, it would be a waste of efforts if the maritime industry and governments were making inefficient use of existing research and development resources and thereby were unable to identify the major obstacles for shipping in the Arctic, and implications of technology developments for the further reduction of on-board manning (i.e., autonomous shipping), ascribing instead its development efforts to deficiencies among the least important criteria as identified in this paper, and thereby erroneously initiated and/or continued with an investment program not highlighting the most important criteria.

By combining the debates on developments of container shipping in the Arctic and autonomous shipping, a theoretical framework on conditions and criteria for long-run decision making is presented as a MCDM framework. The implementation of the MCDM framework using the BWM reveals possibilities for deploying autonomous ships for future expansion of intercontinental transit shipping across the Arctic Ocean, as well as domestic and coastal shipping in Arctic waters. Based on a sample of sixteen academic and industrial experts from Norway, Finland, Australia, France and Canada, we find that the conventional ship is the preferred option for initiating commercial container shipping through the Arctic route. However, the SCC controlled semi-autonomous ship and vessel platooning alternatives are promising for the foreseeable future.

The relatively small sample size of 16 respondents could be considered as a limitation of this study. However, the MCDM family of analytical methods does not necessarily need a large sample size, in particular when the respondents are highly experienced and knowledgeable on the surveyed theme. To provide a broader stakeholder perspective on autonomous shipping, future studies can focus on larger sample sizes involving more respondents from different stakeholder groups such as maritime academies, ship-owners, ship managers, ship financing companies, seafarers, insurance companies, regulatory bodies, etc. Furthermore, the proposed MCDM framework can be extended by adding other relevant criteria and ship alternatives including an extension to other shipping market segments such as dry bulk, liquid bulk, and offshore shipping.

Acknowledgements The authors thank the survey participants. Ziaul H. Munim and Halvor Schøyen acknowledge financial support from MARKOM2020 project of the Norwegian government.

Author's contributions Conceptualization: Ziaul H. Munim; methodology and formal analysis: Ziaul H. Munim; data collection: all authors; writing - original draft preparation: Ziaul H. Munim, Rana Saha, Halvor Schøyen, Theo E. Notteboom; writing—review and editing: all authors.

Funding Open access funding provided by University Of South-Eastern Norway.

Open Access This article is licensed under a Creative Commons Attribution 4.0 International License, which permits use, sharing, adaptation, distribution and reproduction in any medium or format, as long as you give appropriate credit to the original author(s) and the source, provide a link to the Creative Commons licence, and indicate if changes were made. The images or other third party material in this article are included in the article's Creative Commons licence, unless indicated otherwise in a credit line to the material. If material is not included in the article's Creative Commons licence and your intended use is not permitted by statutory regulation or exceeds the permitted use, you will need to obtain permission directly from the copyright holder. To view a copy of this licence, visit http://creativecommons.org/licenses/by/4.0/.

\section{References}

1. NSIDC (2019) Summer's not over until bottom melt ends. Retrieved from http://nsidc.org/Arcticseaicenews/files/2019/09/ Figure-3.png. Retrieved 09 Sep 2019 http://nsidc.org/Arcticseai cenews/files/2019/09/Figure-3.png 
2. Melia N, Haines K, Hawkins E (2016) Sea ice decline and 21 st century trans-Arctic shipping routes. Geophys Res Lett 43(18):9720-9728

3. Meng Q, Zhang Y, Xu M (2017) Viability of transArctic shipping routes: a literature review from the navigational and commercial perspectives. Marit Policy Manag 44(1):16-41

4. Stephenson SR, Brigham LW, Smith LC (2014) Marine accessibility along Russia's Northern Sea route. Polar Geogr 37(2):111-133

5. Tseng P-H, Cullinane K (2018) Key criteria influencing the choice of Arctic shipping: a fuzzy analytic hierarchy process model. Marit Policy Manag 45(4):422-438

6. Wang N, Yan B, Wu N, Zhao W-J (2016) Comments on "Case studies of shipping along Arctic routes. Analysis and profitability perspectives for the container sector'"[Transp. Res. Part A: Policy Pract. 66 (2014) 144-161]. Transp Res Part A 94:699-702

7. Furuichi M, Otsuka N and Authority TP (2012) Effects of the Arctic Sea Routes (NSR and NWP) Navigability on Port Industry. IAPH Port Planning and Development Committee (PPDC) Project, presented at IAPH.

8. Schøyen H, Bråthen S (2011) The Northern Sea Route versus the Suez Canal: cases from bulk shipping. J Transp Geogr 19(4):977-983

9. Chang K, He S, Chou C, Kao S, Chiou A (2015) Route planning and cost analysis for travelling through the Arctic Northeast Passage using public 3D GIS. Int J Geogr Inf Sci 29(8):1375-1393

10. Browse J, Carslaw K, Schmidt A, Corbett J (2013) Impact of future Arctic shipping on high-latitude black carbon deposition. Geophys Res Lett 40(16):4459-4463

11. Aksenov Y, Popova EE, Yool A, Nurser AG, Williams TD, Bertino L, Bergh J (2017) On the future navigability of Arctic sea routes: high-resolution projections of the Arctic Ocean and sea ice. Mar Policy 75:300-317

12. Ellis B and Brigham L (2009) Arctic marine shipping assessment 2009 report.

13. Theocharis D, Pettit S, Rodrigues VS, Haider J (2018) Arctic shipping: a systematic literature review of comparative studies. J Transp Geogr 69:112-128

14. Verny J, Grigentin C (2009) Container shipping on the northern sea route. Int J Prod Econ 122(1):107-117

15. Liu M, Kronbak J (2010) The potential economic viability of using the Northern Sea Route (NSR) as an alternative route between Asia and Europe. J Transp Geogr 18(3):434-444

16. Lasserre $F$ (2014) Case studies of shipping along Arctic routes. Analysis and profitability perspectives for the container sector. Transp Res Part A 66:144-161

17. Guy E (2006) Evaluating the viability of commercial shipping in the Northwest Passage. J Ocean Technol 1(1):9-15

18. World-Shipping-Council (2019) World Trade Organization Statistics Database. Retrieved from http://www.worldshipping.org/

19. Ducruet C (2013) Network diversity and maritime flows. J Transp Geogr 30:77-88

20. Notteboom TE (2012) Towards a new intermediate hub region in container shipping? Relay and interlining via the Cape route vs. the Suez route. J Transp Geogr 22:164-178

21. Zhang X, Zhang W, Lee PTW (2020) Importance rankings of nodes in the China Railway Express network under the Belt and Road Initiative. Transp Res Part A 139:134-147

22. Zeng Q, Lu T, Lin KC, Yuen KF, Li KX (2020) The competitiveness of Arctic shipping over Suez Canal and China-Europe railway. Transp Policy 86:34-43

23. Afenyo M, Lin Y, Ng AK and Jiang C (2019) The opportunities and challenges of developing the Arctic area and shipping in Canada. In: Arctic shipping: climate change, commercial traffic and port development. Routledge, pp 216-226
24. Huang L, Lasserre F, Alexeeva O (2015) Is China's interest for the Arctic driven by Arctic shipping potential? Asian Geogr 32(1):59-71

25. Ragner CL (2000) The 21st century - turning point for the Northern Sea Route, Kluwer Academic Publishers, Oslo, 18-20 Nov 1999

26. Jacobsen S and Gronholt-Pedersen J (2019) Maersk explores Arctic shipping route with Russia. Retrieved from https://www.reute rs.com/article/us-Arctic-shipping-maersk/maersk-explores-Arcticshipping-route-with-russia-idUSKCN1TF0WW

27. Morley H (2019) CMA CGM rejects Arctic shipping route Journal of Commerce, Aug 23, 2019

28. Kooij C, Loonstijn M, Hekkenberg R and Visser K (2018) Towards autonomous shipping: operational challenges of unmanned short sea cargo vessels, In: Marine Design XIII, Taylor and Francis Group Espoo, pp 871-880

29. Thieme CA, Utne IB (2017) A risk model for autonomous marine systems and operation focusing on human-autonomy collaboration. Proc Inst Mech Eng Part O 231(4):446-464

30. Rezaei J, Kothadiya O, Tavasszy L, Kroesen M (2018) Quality assessment of airline baggage handling systems using SERVQUAL and BWM. Tour Manage 66:85-93

31. Porathe T, Hoem $\AA S$, Rødseth, ØJ, Fjørtoft KE and Johnsen, SO (2018) At least as safe as manned shipping? Autonomous shipping, safety and "human error" Safety and Reliability-Safe Societies in a Changing World, In: Proceedings of ESREL 2018, Jun 17-21, 2018, Trondheim, Norway

32. Burmeister H, Bruhn C, Rødseth ØJ and Porathe T (2014) Can unmanned ships improve navigational safety? Paper presented at the Proceedings of the Transport Research Arena, TRA 2014, 14-17 Apr 2014, Paris.

33. Jensen $\varnothing$ (2008) Arctic shipping guidelines: towards a legal regime for navigation safety and environmental protection? Polar Rec 44(2): 107-114

34. Bai J (2015) The IMO Polar Code: the emerging rules of Arctic shipping governance. The Int J Mar Coastal Law 30(4):674-699

35. Deggim H (2018) The International code for ships operating in polar waters (Polar Code), In: Sustainable Shipping in a Changing Arctic, Springer, pp 15-35

36. Munim ZH (2019) Autonomous ships: a review, innovative applications and future maritime business models. Paper presented at the Supply Chain Forum: an International Journal.

37. Höyhtyä M, Huusko J, Kiviranta M, Solberg K and Rokka J (2017) Connectivity for autonomous ships: Architecture, use cases, and research challenges. Paper presented at the 2017 International Conference on Information and Communication Technology Convergence (ICTC)

38. Yuan C-Y, Hsieh C-H, Su D-T (2019) Effects of new shipping routes on the operational resilience of container lines: potential impacts of the Arctic Sea Route and the Kra Canal on the Europe-Far East seaborne trades. Marit Econ Logist 22:308-325

39. Cariou P, Cheaitou A, Faury O, Hamdan S (2020) The feasibility of Arctic container shipping: the economic and environmental impacts of ice thickness. Mar Econ Logist. https://doi.org/10. 1057/s41278-019-00145-3

40. IMO (2018, 25.05.2018) IMO takes first steps to address autonomous ships. IMO. Retrieved from http://www.imo.org/en/Media Centre/PressBriefings/Pages/08-MSC-99-MASS-scoping.aspx

41. Kretschmann L, Burmeister H-C, Jahn C (2017) Analyzing the economic benefit of unmanned autonomous ships: an exploratory cost-comparison between an autonomous and a conventional bulk carrier. Res Transp Bus Manag 25:76-86

42. Rødseth $\varnothing$ (2017) From concept to reality: Unmanned merchant ship research in Norway, In: Proceedings of Underwater Technology (UT), IEEE, Busan, Korea 
43. Meersman H, Moschouli E, NanwayBoukani L, Sys C, van Hassel E, Vanelslander T, Van de Voorde E (2020) Evaluating the performance of the vessel train concept. Eur Transp Res Rev 12:1-11

44. IACS (2006) Requirements concerning polar class. Retrieved from: http://www.iacs.org.uk/search-result?query=polar

45. Heffner K and Rødseth ØJ (2019) Enabling technologies for maritime autonomous surface ships, In: Journal of Physics: Conference Series, IOP Publishing, 1357(1): 012021)

46. Höyhtyä M, Martio J (2020) Integrated satellite-terrestrial connectivity for autonomous ships: survey and future research directions. Remote Sens 12(15):2507

47. Porathe $\mathrm{T}$ (2014) Remote Monitoring and Control of Unmanned Vessels-The MUNIN Shore Control Centre. Paper presented at the Proceedings of the 13th International Conference on Computer Applications and Information Technology in the Maritime Industries (COMPIT '14)

48. NOVIMAR $(\mathrm{n}, \mathrm{d})$ NOVIMAR and the vessel train concept. Retrieved from https://novimar.eu/concept/

49. Van Den Boogaard M, Feys A, Overbeek M, Le Poole J and Hekkenberg R (2016) Control concepts for navigation of autonomous ships in ports. Paper presented at the Proceedings of the tenth symposium high-performance marine vehicles

50. Sanden S, Hovland G (2017) Inverse kinematic control of an industrial robot used in Vessel-to-Vessel Motion Compensation. Paper presented at the 2017 25th Mediterranean Conference on Control and Automation (MED)

51. Deggim H (2013) Ensuring safe, secure and reliable shipping in the Arctic Ocean. In: Environmental security in the Arctic Ocean. Springer, Dordrecht, pp 241-254

52. Schröder C, Reimer N, Jochmann P (2017) Environmental impact of exhaust emissions by Arctic shipping. Ambio 46(3):400-409

53. Solakivi T, Kiiski T, Ojala L (2019) On the cost of ice: estimating the premium of Ice Class container vessels. Marit Econ Logist 21(2):207-222

54. Theotokas I, Progoulaki M (2007) Cultural diversity, manning strategies and management practices in Greek shipping. Marit Policy Manag 34(4):383-403

55. Paris C (2017) Norway takes lead in race to build autonomous cargo ships. Wall Str J. Retrived from https://www.wsj.com/artic les/norway-takes-lead-in-race-to-build-autonomous-cargo-ships1500721202

56. Kitagawa $\mathrm{H}$ (2008) Arctic routing: challenges and opportunities. WMU J Mar Aff 7(2):485-503

57. Lasserre F, Pelletier S (2011) Polar super seaways? Maritime transport in the Arctic: an analysis of shipowner's intentions. J Transp Geogr 19(6):1465-1473

58. Farre A, Stephenson S, Chen L, Czub M, Dai Y, Demchev D, Efimov Y, Graczyk P, Grythe H, Keil K, Kivekäs N, Kumar N, Liu N, Matelenok I, Myksvoll M, O’Leary D, Olsen J, Pavithran APS, Petersen E, Raspotnik A, Ryzhov I, Solski J, Suo L, Troein C, Valeeva V, van Rijckevorsel J, Wighting J (2014) Commercial Arctic shipping through the Northeast Passage: routes, resources, governance, technology, and infrastructure. Polar Geograp 37(4):298-324. https://doi.org/10.1080/1088937X.2014.965769

59. Johansen TA, and Perez T (2016) Unmanned aerial surveillance system for hazard collision avoidance in autonomous shipping. Paper presented at the 2016 International Conference on Unmanned Aircraft Systems (ICUAS)

60. Milaković AS, Gunnarsson B, Balmasov S, Hong S, Kim K, Schütz P, Ehlers S (2018) Current status and future operational models for transit shipping along theCurrent status and future operational models for transit shipping along the Northern Sea Route. Mar Policy 94:53-60

61. Liu N (2013) European Union's potential contribution to enhanced governance of Arctic shipping. Zeitschrift Fur Auslandisches 73:705-733
62. Deggim H (2009) International requirements for ships operating in polar waters. International Maritime Organization, London, $p$ 7

63. Wróbel K, Montewka J, Kujala P (2017) Towards the assessment of potential impact of unmanned vessels on maritime transportation safety. Reliab Eng Syst Saf 165:155-169

64. Comer B, Chen C and Rutherford D (2018) Relating short-term measures to IMO's minimum 2050 emissions reduction target. In: International Council on Clean Transportation. Retrieved from

65. Buixadé Farré A, Stephenson SR, Chen L, Czub M, Dai Y, Demchev D, Keil K (2014) Commercial Arctic shipping through the Northeast Passage: routes, resources, governance, technology, and infrastructure. Polar Geogr 37(4):298-324

66. Kongsberg-Maritime (2021) Autonomous ship project, key facts about YARA Birkeland. URLhttps://www.km.kongsberg.com/ks/ web/nokbg0240.nsf/AllWeb/4B8113B707A50A4FC125811D0 0407045

67. Allal AA, Mansouri K, Youssfi M and Qbadou M (2018) Toward energy saving and environmental protection by implementation of autonomous ship. Paper presented at the 2018 19th IEEE Mediterranean Electrotechnical Conference (MELECON).

68. Chircop A (2009) The growth of international shipping in the Arctic: is a regulatory review timely? Int J Mar Coastal Law 24(2):355-380

69. Ringbom H (2019) Regulating autonomous ships-concepts, challenges and precedents. Ocean Dev Int Law 50:141-169

70. Rezaei J (2016) Best-worst multi-criteria decision-making method: some properties and a linear model. Omega 64:126-130

71. Kusi-Sarpong S, Gupta H, Sarkis J (2019) A supply chain sustainability innovation framework and evaluation methodology. Int J Prod Res 57(7):1990-2008

72. Munim ZH, Sornn-Friese H, Dushenko M (2020) Identifying the appropriate governance model for green port management: applying analytic network process and Best-Worst methods to ports in the Indian Ocean Rim. J Clean Prod 268:122156

73. Bai C, Kusi-Sarpong S, Badri Ahmadi H, Sarkis J (2019) Social sustainable supplier evaluation and selection: a group decisionsupport approach. Int J Prod Res 57(22):7046-7067

74. Liang F, Brunelli M, Rezaei J (2019) Consistency issues in the best worst method: measurements and thresholds. Omega 96:102175

75. Yağdereli E, Gemci C, Aktaş AZ (2015) A study on cyber-security of autonomous and unmanned vehicles. J Def Model Simul 12(4):369-381

76. Kavallieratos G, Katsikas S and Gkioulos V (2018) Cyber-attacks against the autonomous ship, In: Computer security Springer, pp $20-36$

77. Lee T, Kim HJ (2015) Barriers of voyaging on the Northern Sea Route: a perspective from shipping Companies. Mar Policy 62:264-270

78. Faury O, Cariou P (2016) The Northern Sea Route competitiveness for oil tankers. Transp Res Part A 94:461-469

79. Cariou P, Faury O (2015) Relevance of the Northern Sea Route (NSR) for bulk shipping. Transp Res Part A 78:337-346

80. Marchenko N, Andreassen N, Borch OJ, Kuznetsova S, Ingimundarson V, and Jakobsen U (2018) Arctic shipping and risks: emergency categories and response capacities, In: Marchenko N, Andreassen N, Borch O (Eds) International Journal on Marine Navigation and Safety of Sea Transport, 12(1): 107-114.

Publisher's Note Springer Nature remains neutral with regard to jurisdictional claims in published maps and institutional affiliations. 